\title{
Present-Day Key Roles In Nursing Administration
}

\author{
Rebecca Bergman, D.Ed., M.A., B.Sc. \\ Clinical Professor of Nursing, Tel Aviv University, Israel
}

Address given at the Second International Symposium, 14 and 15 April 1978, at the University of South Africa, presented by the Pretoria Branch of the S.A. Nursing Association under the auspices of the Department of Health

\section{OPSOMMING}

Vier uitdagende aspekte i.v.m. administrasie is as die grondslag van doeltreffende verpleegadministrasie gekies. Hulle is programbeplanning, evaluering, persoonlike verhoudings en mannekragontwikkeling. G'n een van hulle staan alleen nie; om effektief te wees moet elkeen die steun van die ander drie hê.

Present-day nursing administration has many goals, roles and functions. Predominant among the roles are those of: programme planner. manager of material resources, manager of human resources, educator, clinician and researcher. These and other roles relate to clients, colleagues, the agency. the community and the profession. The roles are not discrete, but overlap and intertwine with each other and with the roles of other care providers.

From the many challenging aspects of nursing administration. I have selected four which I believe are the foundations for effective nursing administration

(1) programme planning - the long-range approach in lieu of ad hoc action

(2) evaluation - at all stages and on completion of a programme

(3) interpersonal relations - the component that oils or clogs the machinery of service

(4) manpower development - of human resources who influence the utilisation of material resources.

These four roles provide the basic tools for leadership as defined by Bennes (1964): " building an effective team or constellation, and developing a climate in which collaboration will flourish."

\section{PROGRAMME PLANNING}

Planning of nursing service is built upon the philosophy and technologies of nursing and administration. It aims to provide quality nursing service for patient, family and community health.

Major steps in the planning process are: pre-plan - i.e. determine if essential basic preconditions are available; determine needs and resources of the community to be served; set priorities; develop a plan with alternatives; involve important others; prepare budget, personnel and facilities; implement the plan with ongoing supervision; evaluate and report.

(a) In preplanning one must be cognizant of: attitudes of the decision-makers to nursing; existence of laws that can promote or restrict the programme; availability or potential of an organisational framework to implement the programme.

Presence of most of the preconditions permits the planners to continue as envisioned. Partial existence may require modification or limitation of the tentative plan. Absence of the preconditions may require time and effort to create change in the preconditions or the plan may be given up for the time being.

(b) The next step is to obtain an overview of needs and resources. Data should include present status and pro- 
jected trends of the "community" which may be nationwide, regional, district, local, or even one institution or clinic. It should be emphasised that much valuable data, often unused, is available in official reports. special studies, etc.

We should clarify which needs are "nursing needs." A nursing need is defined by Freeman (1963) as a "health need where nursing can make a difference." While nurses should be flexible in accepting functions, they must recognise that better utilisation and satisfaction can be attained by focussing on services for which the practitioners have been prepared.

The survey of resources for health care includes health-related services such as education, social welfare; and health programmes / facilities such as hospitals or clinics. Human resources must alsu be studied: health professionals (employed, unemployed and in training), volunteers. community groups and leaders.

(c) Knowledge of the needs and resources permits identification of specific problems. Priorities can be determined by weighing four main factors: importance of the needs, availability of resources, client readiness for agency intervention, and legal aspects.

(d) Conceptualisation of possible alternatives to meet the needs comes next. The selected alternative is then developed into a plan, starting with a statement of broad aims.

Out of the aims, which are actually statements of what it is hoped can be accomplished, a set of operational objectives are developed. These are clear statements of what is planned to be achieved in terms of quantity, quality, time, etc. Although the objectives are stated very specifically so that outcome can be measured against anticipated achievement, it does not mean that they cannot be changed if there is good reason for same. Objectives should relate to short- and long-term plans; relevant aspects of promotive, preventive, curative, rehabilitative and custodial nursing care; and education / development of clients, the community as a whole and of staff.

(e) It is desirable to involve others who will participate in the programme as early as possible. This includes other professionals, agencies, community leaders and representation of clients. Planners can obtain valuable ideas from the newcomers and should be ready to change plans as new aims, objectives or methods emerge.

(f) The budget is built on the items developed in the operational plan; staffing (including staff development), facilities, equipment and transport. The proposed budget must be built on facts and logic. It is possible that all or part of a proposed programme can be carried out by existing personnel and volunteers. Changes might be made in the scope of service in an existing programme, or personnel might be freed for new assignments by improved efficiency in their present jobs. However. more and different staff are usually needed for a new programme. Based on the job descriptions in the operattional plan. criteria for recruiting and selection are determined. If personnel are available but lack some of the needed qualifications. a supplementary educational programme may be developed. The role of families and volunteers in the care of home-bound or institutionalised patients is important and should be taken into account.

Facilities and equipment can be prepared concurrently with personnel recruitment and development. Available resources may be adequate, require adaptation or new resources may be needed. Consideration should be given to the functions of the service such as diagnosis / treatment / teaching / research, as well as to the needs of personnel and the supportive services office space. laundry, records. conference and rest rooms.

(g) The first step in implementation, if not already done, is to inform all those involved of the service to be introduced. At every stage of the programme there should be open (wo-way communication between administration. staff and clients. On-going supervision and guidance for all levels of personnel will facilitate safety. effective implementation and serve as a channel for flow of ideas.

(h) On-going evaluation of process and outcome should be used for flexible replanning as indicated at any stage. The final evaluation should measure the achievement of the objectives against a baseline recorded at the beginning of the programme. Evaluation should analyse the input in human time and effort. cost of equipment and facilities, in order to determine if the results justify the investment.

The final report is the major tool for replanning continuing or terminating the programme. It can also be used as a guide in planning other programmes. It should be comprehensive, covering the entire plan. thus completing the cycle of programme planning from preplanning to end evaluation.

\section{EVALUATION}

Evaluation, the second aspect to be discussed, will focus on approaches, not techniques. My examples will mostly relate to community nursing.

Evaluation was defined by WHO (1967) as "a process which measures the degree to which objectives and targets are fulfilled, and the quality of the results obtained. It measures the productivity of available resources in achieving clearly defined objectives. It measures how much output or cost-effectiveness is achieved. It makes possible the reallocation of priorities and resources on the basis of changing health needs." 
Three major points of departure for evaluation are: structure, process and outcome.

Study of the structure of an agency assumes that if it meets required standards, then the level of service should also meet expectations. This approach is probably the easiest to implement. It includes examination of the quality and quantity of staff, organisation of the agency - communication channels, levels and flow of decision-making. etc. as well as agency policy and philosophy.

Process relates to the activities carried out to achieve objectives. Time studies and activity studies give the answers to who. what. where, and when. They show the scope of activities in various sections of the programme and whether the input was appropriate to the goals. Analysis also shows whether staff are being utilised at their level of preparation and experience. Selection of analysis of process infers that there is a direct relationship between quantity and quality of input to the level of outcome.

Measure of outcome is the most difficult method of evaluation. The patient progress method, developed and described by Roberts \& Hudson (1963) is an excellent tool for study of outcome. This method requires categorisation of needs of the clients, severity of the need. expected outcome, care given and measure of the actual outcome. thus showing the change in need against the initial status and a realistic goal. The same technique is used for groups or communities, thereby obtaining a picture of the degree of achievement in meeting each need area for the specific group.

In evaluating nursing services I think that there are three cardinal aspects to be considered.

(a) Effectiveness of the service, i.e. achievement of goals and the permanence of change;

(b) efficiency of the service i.e. how well resources have been used to achieve the goals;

(c) impact on the providers of service and on the profession of nursing.

At the danger of oversimplification. I would like to pose several "common sense" questions for each of the above aspects. Some answers may be sought through sophisticated research, others from expert opinion, by consultation with peers, or simply by looking. listening and thinking.

\section{Effectiveness}

Several questions need to be asked in order to evaluate effectiveness.

(1) Does the programme relate to real needs? Goals at national or regional level often have little relationship to local needs. Professionals may identify "needs" based on their own values and later find that the "problems" were adequately solved by the clients themselves without outside intervention.
(2) Are the services reaching those who need them?

Do the non-users need the service?

What steps can close the gap between need and supply?

(3) Is the service adequate and accessible?

(4) Is the service comprehensive? Does it integrate and balance promotion of health, prevention, treatment and rehabilitation?

(5) Does it provide for continuity of care between curative and preventive services, from in-patient to out-patient facilities, from one profession to another. from agency to agency?

(6) Are clients satisfied with the service? Do they take part in development of plans?

\section{Efficiency}

Areas to be reviewed for evaluation of efficiency include the use of human and material resources to achieve goals:

(1) Is there duplication or conflict between agencies or between aspects of a programme within an agency?

(2) Is the quantity, quality and "mix" of personnel suited to the programme?

(3) Are facilities and equipment fully utilised?

(4) Are the monetary costs in line with expenditures in similar programmes in comparable conditions? Is there evidence of wastage or dishonesty?

While effectiveness is primarily client-focussed, and efficiency is agency-focussed, impact on personnel and the nursing profession has meaning for both clients and agencies.

\section{Impact On Nursing}

Some points to note in relation to manpower and the profession are:

(1) Do the staff identify with their work? Are they stimulated? Do they feel they have the support of their supervisors and colleagues?

(2) Is there evidence of continued personal and professional growth of staff members? Are learning experiences at work and planned educational programmes encouraged?

(3) Are the nurses moving towards more independent functioning as well as inter-dependent colleague relations with members of other disciplines?

(4) Is the programme enriching nursing education by providing student practice, developing learning materials and methods? 
(5) Are contributions to the profession growing out of the community practice and research which can serve as guidelines, principles, models or theories?

Evaluation should ask relevant questions in an appropriate way, and utilise the answers to improve service.

\section{INTERPERSONAL RELATIONS}

The historic meeting of Prime Minister Begin and President Sadat in Jerusalem. which was watched all around the world. highlighted the tremendous potential impact of faceto-face interpersonal relations. The thirty-year wall of hostility crumbled in $4+$ hours. But this dramatic event had a broader base than the courage and charisma of the participants. Claus and Bailey (1977) conceptualised personal (characteristics and self concept), interpersonal (interaction with others). and organisation (official status) as three sides of the power pyramid. These three are closely interrelated and these contribute to attaining formal power. Similarly. power stat us opens the door to interpersonal involvement and enhances the self-image. Needless to say. just as power is built from development of the three components - so it can be destroyed if they are not revitalised by personal growth. dynamic co-operative interpersonal involvement, and by constructive use of organisational position.

The authors further depict three dimensions within each power-base: strength (ability). energy (will) and action (doing by self and motivation of others). On the interpersonal base this could be interpreted as (1) knowledge of what others have to offer, understanding of their motivations and skills in communication; (2) the will to interact with others - to learn and teach, give and take, value and be valued: and (3) to initiate and respond to co-operative interpersonal action.

However. there are many obstacles to overcome. A medical doctor who is the director of a multi-disciplinary educational programme in Australia recently wrote the following (personal communication):

“Our experience leads us to believe that at the level of inter-personal relations among members of the health team. the main problem is ignorance combined with a lack of skills in teamwork and communication. By ignorance 1 mean a lack of understanding or awareness of the contributions that others have to make, which is often complicated by a rather sinister lack of confidence in a professional's own contributions. It would seem that the people who find it most difficult to work with others are those who have low self-esteem and very little selfconfidence. which lead them to hide behind the technical and ritual aspects of their own profession."

The above statement neatly fits the Claus-Bailey model, and points out some of the major impediments to positive inter-personal relations. I should like to analyse some of the problems, and propose possible action, as I believe that we ourselves - the administrators and educators - can and must be change agents - to improve inter-personal relations between client and practitioner. between disciplines, and within nursing.

Lack of appreciation of the actual and potential role of the patient. family and colleagues often results in inter-personal tensions. under-utilisation or misuse of resources, overlap of services, and even conflicting treatment. With so much at stake it is difficult to understand why the area of interpersonal relations has been neglected so long. Why haven't patients. doctors. nurses or others demanded a system to promote productive inter-personal relations? Perhaps the recipient of care has been too much in awe of the omnipotence of the professional to raise his voice. Because his need is so great he may not wish to endanger his care by challenging accepted behaviour. Nurses, influenced by their traditional role of handmaiden to the doctor, have until recently accepted a subservient position. Members of younger professions in the health field, are less inhibited by the past and therefore more likely to achieve peer status in the health team. With the increasing level of general and professional education one finds nurses and other members of the health team moving from submissive dependence, to defensive independence and hopefully towards co-operative interdependence.

However. if the road to interdependence is strewn with obstacles. defiance and competition may become established alternatives.

What can be done to improve interpersonal relations? Education of practitioners does not take place in a vacuum. It influences and is influenced by the accepted modes of praclice and professional ethics; it is further facilitated or impeded by the administrative selting in which the practice is implemented.

The client-practitioner relationship can only change from submission-domination to co-operation when the practitioner's philosophy of practice is based on respect for the patient as a person. and when the practitioner accepts the client's right and ability to be a partner in decisions concerning his well-being.

How can management enhance client/practitioner relations? Management can bolster the patient's position by taking his complaints and suggestions seriously. Studies of the level of satisfaction with care is another approach. Auditing records for evidence of patient/family involvement in care would indicate if, where and when intervention was desirable. Sufficient staff, as well as suitable physical facilities, should provide an environment for relaxed patient/practitioner interaction.

Professional education should provide a philosophical, social and behavioural science base which will enable the practitioner to respect and understand others. Subjects such as philosophy, ethics, sociology, anthropology and psychology should be included. Education must also provide learning experiences in developing communication skills - listening. observing, encouraging, contributing, interpreting, summarising. 
Let us now look at inter-personal relations among members of the health team. In practice. depending on the individuals and the circumstances, relations may range along a positive-negative continuum from mutual respect and cooperation to passive agreement, benevolent paternalism, authoritarianism. conflict and rebellion.

Management can establish inter-disciplinary councils. committees or teams at appropriate le vels of operation. If the involved professionals are interested and capable they will soon establish a relationship which will enable them. by personal example. to further a system of combined planning and sharing among their colleagues in the operational units. Good co-operation of a doctor/nurse/business manager team in the hospital administration will soon be reflected in the relationships on the wards.

Integrating values and skills for teamwork throughout the educational programme is probably the most effective method for developing positive inter-personal relations among health professionals. There are several avenues, often more effective if used in combination. One of these is courses taught by teachers of various professions in which they interpret their unique function and integrated role. Another is to offer joint core theoretical courses and/or combined clinical experiences. Many educators have placed their hopes in the health science schools, but they have yet to prove themselves.

All of the principles and techniques in the client/practitioner and inter-disciplinary areas apply equally to inter-personal relations within nursing. Administrators have to be as ready to give the same respect to staff, that they want to receive from the ir seniors or colleagues. Professional nurses must understand that there is a level of excellence in the work of auxiliaries and that all levels of nursing personnel have much to contribute to patient care and smooth functioning of the service. And what are we doing about the overt or covert teaching-service, hospital-public health conflicts"? We have, I believe, the "strength" and "energy" — we need to apply them to "action" in our inter-disciplinary relations.

As shown above. there is no single way to achieve improved inter-personal relations. It requires the combined efforts of administration and education. and needs to look at all levels and areas where people study. meet and work in the health field.

\section{MANPOWER DEVELOPMENT}

The fourth major nursing administration role. manpower development, is defined in this paper as "preparation and growth of nursing personnel in order to improve nursing service and promote personal satisfaction."

Sources of supply of nursing manpower are: schools of nursing, immigration. unemployed nurses, and untapped potential of employed nursing personnel. What is the role of the nursing administrator in manpower development from each of the above sources? (a) Review of the literature. and our own experience. shows a swing of the pendulum from control of schools of nursing by the nursing service administrator. to her complete exclusion or disengagement and. more recently. back to a consultant partnership relattionship between service and education leaders. I believe that educators should carry the responsibility for the aducaltional programme. but they need to recognise the importance of dialogue with service administrators on present and predicted needs for quality and quantity of personnel. Institution and community are the arena for most student field experiences. and require combined planning and supervision by the administrators. faculty and staff. In addition. feedback from the field on the achievements and problems of students and graduates can serve as a base for evaluation and revision of the educational programme.

(b) A second source of nursing manpower is immigration. In 1972 and 1973, more foreign nurses entered Israel than were graduated in all the local schools. Mejia (1976) states that about 135000 nurses. $4 \%$ of the world nurse population, are outside of their own country. Immigrant nurses may never reach their potential unless the proper authorities together with nursing administrators develop a plan for their social and professional absorption. This includes such steps as examination of credentials. provision of supplementary studies in order to meet the local standards. referral to agencies for work. orientation programmes, open-door policy and followup by the nursing office. and last, but not least, concern for social integration into the agency and community.

(c) Much research has been conducted on the non-active nurse. Findings show that four main conditions were given as preconditions for return to work: arrangements for care of their children. interesting work. flexible work schedule and refresher courses. The nursing administrator can play a major role in providing all of these conditions. The Israeli work-life study of registered nurses (Bergman. 1975) found a relationship between full. part-time or inactive work status and the number of children. as well as the age of the youngest child -- that is to say that children and their care were the main reatson why mothers did not work. Considerable efforts have been made to provide funds and/or facilities for the care of the nurses young children. Matching available positions 10 candidates with interest in that type of work. as well as encouraging initiative and autonomy, answer the need for interesting work. Employment for part-time work, single shifts, coverage of a position by a team of part-time nurses are but a few of the avenues open to nurse administrators to enable flexible work schedules. Refresher courses are a must. not only for the nurses. self-confidence and for safety of care, but also as a medium for identifying abilities that can be utilised when the opportunity arises. If available positions remain unfilled, the nurse administrator should reach out into the community to recruit non-active nurses. Retain- 
ing contact with graduates and former staff members may facilitate return to work when needed.

(d) The major role of the nursing administrator in manpower development is, I believe, in recognising and promoting potential among employed nursing staff. This has been stated succinctly by ICN in its policy statements on "career mobility" and "continuing education." Administrators can play a crucial role in developing a system which will facilitate the achievement of new career goals by the personnel in their agencies. These goals may be:

1. from a lower to a higher category in the nursing personnel system. e.g. practical nurse to RN

2. along the hierarchical ladder, e.g. staff to head .... nurse.

3. from one field to another, e.g. public health to education.

I believe that:

1. Every individual should be helped to reach his maximum potential by encouragement and material assistance.

2. Mobility programmes should be built upon previous formal and informal learning experiences and minimise repetition.

3. Standards achieved by the participants of mobility programmes should be equitable to those of graduates of regular programmes of the same level.

4. Career mobility will contribute to nursing manpower resources by raising the qualifications of personnel, by increasing satisfaction and thereby effectiveness, and by retaining personnel in nursing who would leave if not enabled to progress.
In Israel the Ministry of Heallh and other major algencies together with the nurses" association have developed a system in which nursing personnel who have demonstrated ability and motivation. are helped 10 progress to a higher level of preparation and/or more desirable function. This is true for the aide who wishes to enter a formal nursing education programme. as well as for the nurse who holds an academic degree and wants to continue study at the master or doctoral level. Short-term recognised courses are accorded points which on accumulation are rewarded by a salary increase.

You are probably thinking that this is a complicated and difficult undertaking for the nurse administrator. You are absolutely correct - but it is also one of her greatest sources of satisfaction, and an important way of providing the right people to fill the right job at the right time.

I have attempted to share with you some thoughts about four key roles of the nursing administrator: programme planning. evaluation, inter-personal relations, manpower development. None of these stands alone. in fact each of them must have the support of the other three roles in order to be effective. Of necessity the roles have been overly simplified - each is a topic for a full symposium. However. if this paper has served to either strengthen your beliefs (and action) or, by being controversial, has stimulated your thinking, then its purpose has been achieved.

\section{REFERENCES}

1. Bennes. W.: "Post-bureaucratic Leadership," Trans-Action, 44:61. July/August, 1964

. Bergman. R. et al: "Worklife of the Israeli Registered Nurse." International Journal of Nursing Studies, 12(3): 135-170. October. 1975

3. Claus. K. \& Bailey. J . Power and Influence in Health Care, St Louis: Mosby. 1977

4. Freeman. R.: Public Health Nursing Practice, Philadelphia: Saunders, 1963 . Mejia. A.: "World Migration of Heallh Manpower," WHO Chronicle, 30(11): 455460 . November. 1976

6. Roberts. D. \& Hudson. H. : How to Study Patient Progress (PHS Publication No

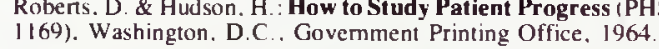

7. World Health Organisation Expert Committee on National Health Planning in Developing Countries. World Health Organisation Techn. Rep. Ser., No. 350. Geneva: WHO 1967 